\title{
CT angiography predicts use of tertiary interventional services in acute ischemic stroke patients
}

\author{
Lisa E Thomas ${ }^{1}$, Joshua N Goldstein ${ }^{1 *}$, Reza Hakimelahi ${ }^{2}$, Yuchiao Chang ${ }^{3}$, Albert J Yoo ${ }^{2}$, Lee H Schwamm ${ }^{4}$ and \\ R Gilberto Gonzalez ${ }^{2}$
}

\begin{abstract}
Background: Patients with acute stroke are often transferred to tertiary care centers for advanced interventional services. We hypothesized that the presence of a proximal cerebral artery occlusion on $\mathrm{CT}$ angiography (CTA) is an independent predictor of the use of these services.

Methods: We performed a historical cohort study of consecutive ischemic stroke patients presenting within $24 \mathrm{~h}$ of symptom onset to an academic emergency department who underwent emergent CTA. Use of tertiary care interventions including intra-arterial (IA) thrombolysis, mechanical clot retrieval, and neurosurgery were captured.

Results: During the study period, 207/290 (71\%) of patients with acute ischemic stroke underwent emergent CTA. Of the patients, 74/207 (36\%) showed evidence of a proximal cerebral artery occlusion, and 22/207 (11\%)

underwent an interventional procedure. Those with proximal occlusions were more likely to receive a neurointervention ( $26 \%$ vs. $2 \%, p<0.001)$. They were more likely to undergo IA thrombolysis ( $9 \%$ vs. $0 \%, p=0.001)$ or a mechanical intervention (19\% vs. $0 \%, p<0.0001)$, but not more likely to undergo neurosurgery ( $5 \% \mathrm{vs.} 2 \%, p$ $=0.2$. . After controlling for the initial $\mathrm{NIH}$ stroke scale (NIHSS) score, proximal occlusion remained an independent predictor of the use of neurointerventional services (OR 8.5, 95\% Cl 2.2-33). Evidence of proximal occlusion on CTA predicted use of neurointervention with sensitivity of $82 \%$ (95\% Cl 59-94\%), specificity of $71 \%(95 \% \mathrm{Cl} 64 \%-77 \%)$, positive predictive value (PPV) of 25\% (95\% Cl 16\%-37\%), and negative predictive value (NPV) of 97\% (95\% Cl 92\%99\%).
\end{abstract}

Conclusion: Proximal cerebral artery occlusion on CTA predicts the need for advanced neurointerventional services.

\section{Background}

Regional systems of care have been established in some localities, where acute ischemic stroke patients are preferentially admitted to "stroke centers" [1,2]. However, no formal guidelines exist for determining which patients should be transferred from a primary stroke center (PSC), capable of administering thrombolysis, to a comprehensive stroke center (CSC), with advanced services including endovascular capabilities. As a result, there can be tremendous heterogeneity in which

\footnotetext{
* Correspondence: jgoldstein@partners.org

'Department of Emergency Medicine, Massachusetts General Hospital, Boston, MA, USA

Full list of author information is available at the end of the article
}

patients remain at a PSC versus which are transferred to a CSC. Furthermore, many PSCs are likely capable of providing maximal management to stroke patients and may reserve transfer for those who need additional services available only at a CSC $[3,4]$.

Efficient resource allocation may best be achieved by reserving such transfers for patients who will receive the most benefit. A rapidly available tool that predicts which patients are interventional candidates would help emergency physicians determine who might benefit from transfer to a CSC.

One candidate for such a tool is CT angiography (CTA), which can reliably detect large occlusive thrombi in proximal cerebral arteries [5]. While only $25-35 \%$ of

\section{空 Springer}

(c) 2011 Thomas et al; licensee Springer. This is an Open Access article distributed under the terms of the Creative Commons Attribution License (http://creativecommons.org/licenses/by/2.0), which permits unrestricted use, distribution, and reproduction in any medium, provided the original work is properly cited. 
patients with acute ischemic stroke have such occlusions, they are disproportionately responsible for high hospital costs, morbidity, and mortality [6,7]. As intravenous (IV) recombinant tissue plasminogen activator (rtPA) is less effective in recanalizing proximally occluded vessels [8], these individuals may preferentially benefit from advanced therapies at tertiary care centers. In particular, intra-arterial thrombolysis $[9,10]$, mechanical clot disruption [11,12], and device-aided thrombus extraction [13-15] have been shown to recanalize occluded vessels at a rate higher than for IV rtPA, which may lead to better outcome [16]. Since multislice CT scanners are available $24 / 7$ in the majority of US emergency departments [17], it may be that this technology can be harnessed to select patients for transfer.

We hypothesized that the presence of an occlusive thrombus in a proximal cerebral artery on CTA is an accurate predictor of the use of advanced neurointerventional services. We elected to perform an observational study at a center in which virtually all patients undergo emergency CT angiography as a clinical standard of care, in order to minimize selection bias.

\section{Methods}

\section{Study design}

This was an historical cohort study of consecutive ischemic stroke patients who presented to a single academic emergency department (ED) and who underwent emergent CTA. The study was approved by our Institutional Review Board.

\section{Setting and selection of participants}

All patients presenting within $24 \mathrm{~h}$ of symptom onset in 2006 to the ED were prospectively captured as described [6]. This hospital is a Massachusetts Department of Public Health-certified Stroke Center and offers a full range of CSC capabilities including tertiary care interventional and neurosurgical services 24/7. Patients requiring such services were treated at our study hospital as needed without being transferred.

Although MR angiography (MRA) can also identify proximal vessel occlusion, we did not include these studies because MRI is not available in the emergency department at most hospitals [17] and is not a required emergent service for PSCs. However, 96\% of hospitals can perform an emergency CT with contrast [17], and so likely have the ability to detect a proximal artery occlusion.

\section{Imaging}

Standard imaging at our center for suspected acute ischemic stroke includes CTA and MRI. CT images were acquired according to standard protocols [6].

\section{Classification of proximal cerebral artery occlusion on CTA imaging}

Presence of a large-vessel proximal occlusive thrombus was defined as described previously [6]. This included obstruction in the distal/terminal (intracranial) internal carotid artery, proximal (M1 or M2) middle cerebral artery, and/or basilar artery (Figure 1). These regions were selected based on a prior study showing that occlusions of these segments were more likely to be associated with larger strokes [18] and based on the likelihood that proximal occlusions in these locations could be readily identified by physicians with minimal training in interpreting CTAs. The original neuroimaging report was reviewed by a neuroradiologist, who was blinded to whether the patient received any IA therapies, to confirm the official interpretations and to clarify any ambiguous descriptions to ensure uniform classification of proximal occlusion for study purposes. In the event of conflicting original and subsequent interpretations, a second neuroradiologist was available to review the images; however there was $100 \%$ interrater reliability with the original interpretation. An example of a patient with a proximal cerebral artery occlusion is shown in Figure 2.

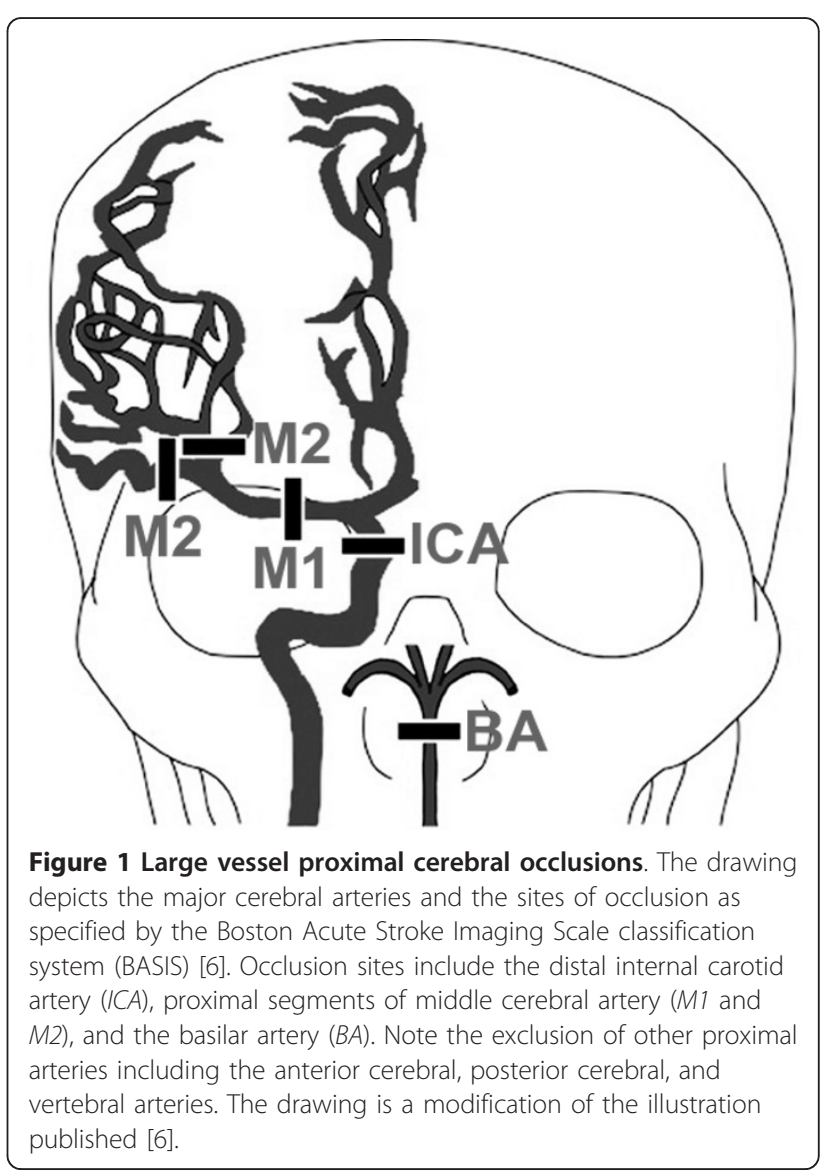




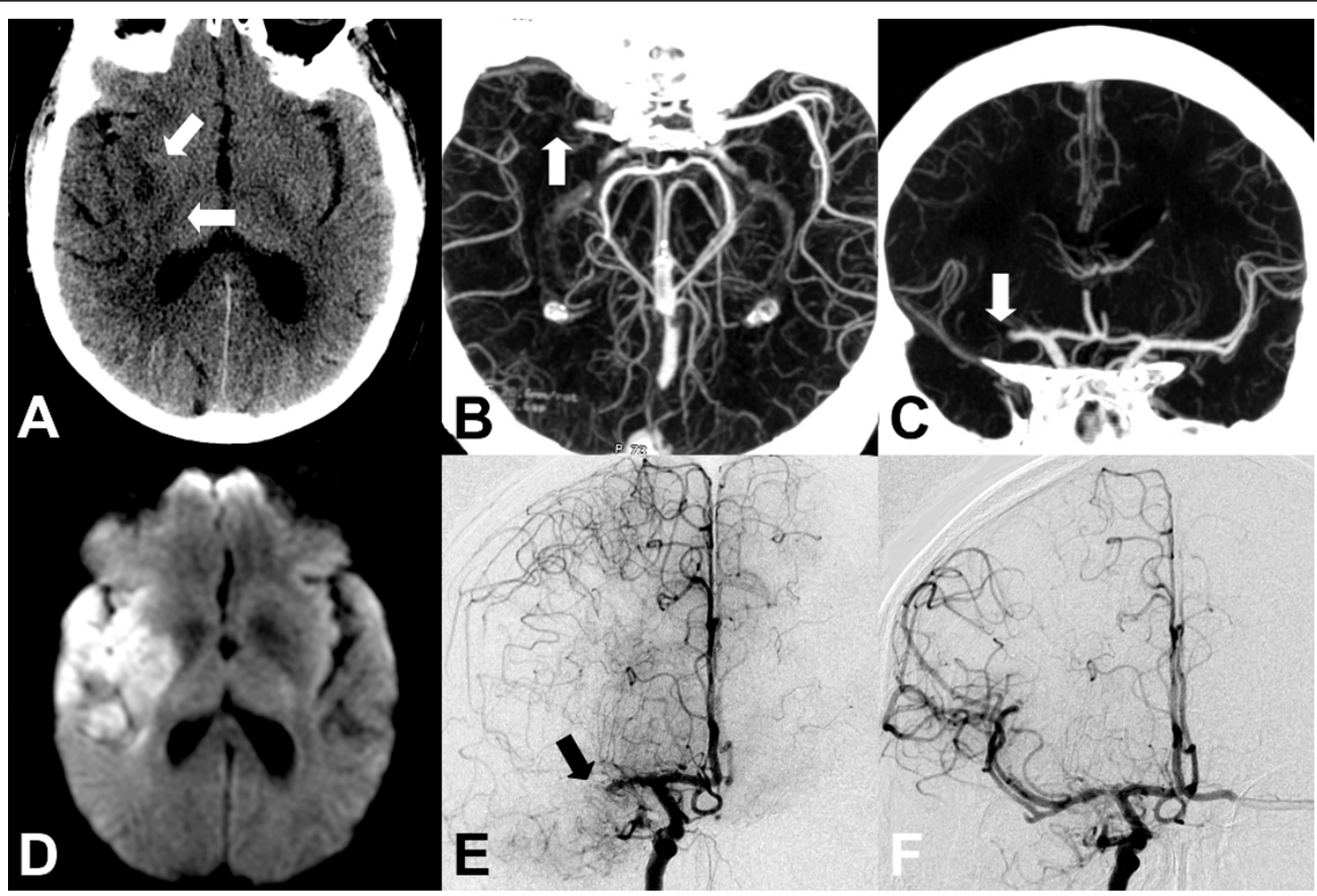

Figure 2 Imaging of patient with proximal cerebral arterial occlusion. Imaging of a 67-year-old male who presented $3 \mathrm{~h}$ after onset of left hemiparesis and aphasia with initial NIHSS of 18 and found to have proximal cerebral arterial occlusion is depicted here. After intra-arterial intervention, he was admitted to the neurosciences ICU, symptoms improved, and he was eventually discharged to a rehabilitation facility. (a) Noncontrast CT shows subtle hypodensity (arrows) in the right basal ganglia in right middle cerebral artery territory. (b) Axial CT angiogram reconstructed at the $\mathrm{CT}$ console immediately after the patient was scanned. The reconstruction was performed using the simple overlapping thick slab maximal intensity projection (MIP) algorithm and clearly shows (arrow) an occlusion of the proximal right middle cerebral artery (M1 segment). MIP parameters included 15-mm slab thickness overlapping at 3-mm intervals. (c) Coronal CT angiogram reconstructed at the CT console at the same time as $\mathbf{b}$ again demonstrates the right M1 artery occlusion (arrow). (d) MRI demonstrates the DWI hyperintense infarct in right MCA distribution. (e) Selective right internal carotid artery angiogram shows abrupt occlusion of blood flow at the right M1 segment (arrow) confirming CTA finding. (f) Post intra-arterial therapy angiography shows restoration of cerebral blood flow in the right middle cerebral artery and its branches.

\section{Outcome measures}

The primary outcomes of interest were use of tertiary care neurointervention, including IA thrombolysis, mechanical clot retrieval or removal, or any neurosurgical procedure. We had $85 \%$ power to detect a $15 \%$ difference in the primary outcome between patients with and without proximal occlusion at the 0.05 level. Decision for the type of treatment used was based on clinical judgment of the treating cerebrovascular specialists. Secondary outcomes included need for ICU admission, length of stay, and disposition after hospital stay (categorized as discharge to home, transfer to a rehabilitation center/skilled nursing facility, or death).

\section{Data analysis}

As most variables were not normally distributed, univariate analyses were performed using the Wilcoxon rank sum test for continuous variables and Fisher's exact test for categorical variables. Due to the small number of outcomes, we included proximal occlusion on CTA and only one additional variable, NIHSS score, in the multivariable logistic regression model. Goodness-of-fit test and regression diagnostics were performed for influential observations. Statistical analyses were performed using STATA software version 10 (STATACorp, College Station, TX).

\section{Results}

During the study period, 290 patients who presented within $24 \mathrm{~h}$ of symptom onset were admitted with acute stroke. Of these, seven were excluded for enrollment in the DIAS-2 clinical trial [19] since the intervention was blinded. Another 76 were excluded for not having a CTA performed (61 had MRA for cerebrovascular imaging and 15 had no vessel imaging because of contraindications to both studies), leaving 207 patients for final analysis. The median time to registration in the ED from the time last seen well was $3.9 \mathrm{~h}$ (IQR 2-5.8 h). 
Thirty-three percent of patients presented within $3 \mathrm{~h}$ of symptom onset, $75 \%$ within $6 \mathrm{~h}$ and $90 \%$ within $12 \mathrm{~h}$. Of this cohort, $25 \%$ of patients received IV $\mathrm{rtPA}, 2.4 \%$ received IA thrombolysis, $6.8 \%$ received a mechanical intervention, 3.3\% underwent surgery (4 decompressive hemicraniectomies and 3 carotid endarterectomies), and $52 \%$ were admitted to the neuroscience ICU.

Table 1 shows patient characteristics among those receiving an advanced neurointervention. Of note, there was no significant difference in rate of IV rtPA use between those who did and did not receive an intervention. Table 2 shows the comparison of patients with and without proximal occlusion. In multivariable logistic regression, proximal occlusion on CTA was an independent predictor of the use of neurointerventional services after controlling for initial NIHSS score (Table 3). Finally, test characteristics for the ability of a proximal cerebral arterial occlusion to predict the need for neurointervention were calculated (Table 4).

\section{Discussion}

We found that proximal cerebral artery occlusion on CTA predicts the use of acute neurointervention. While time to presentation and neurological exam findings are often used in decision-making regarding transfers, this specific radiographic finding appears to add independent value in predicting tertiary care interventions. Use of CTA in selected patients may therefore improve our ability to stratify which patients would benefit from emergent transfer to a CSC.

Although only a quarter of patients with a proximal occlusion actually received a neurointervention, distinguishing those with a large occlusion may be important for two reasons. First, if an occlusion is not seen, it is highly unlikely that a patient will need an intervention. In fact in our study, only $3 \%$ received an intervention without a large occlusion on CTA. All of these were patients with critical internal carotid stenosis that received carotid endarterectomies that were not performed on the same day as admission but during that hospital stay. Thus, most of the patients without proximal occlusion could potentially receive appropriate care at PSCs depending upon resources available. On the other hand, if a proximal occlusion is seen on CTA, these patients should be considered for emergent transfer or at least discussed with a CSC via teleradiology or phone consultation to determine whether they are interventional candidates. Even if they are not, they might still benefit from care at a CSC because they will tend to have larger strokes, worse outcomes [6], and may have more complicated care needs.

The commonly used practice of relying on clinical findings and noncontrast head $\mathrm{CT}$ for management decisions may provide inadequate information for triaging stroke patients for advanced therapies. For example, large artery occlusive strokes may not respond well to IV rtPA, but show better response to IA therapies $[20,21]$. In addition, vascular imaging provides independent information regarding the patient's prognosis [18]. As a result, current American Heart Association (AHA) guidelines endorse vascular imaging in the initial evaluation of the patient with acute ischemic stroke symptoms [22].

Our data confirm findings from others that patients with proximal occlusions tend to have higher NIHSS scores [23-26]. This raises the question of whether the NIHSS score alone can select those patients requiring advanced intervention. We conclude, however, that CTA does add independent value. First, one recent prospective study found that NIHSS alone has a poor negative predictive value for proximal occlusion amenable to intervention [27]. Second, we found that CTA provides

Table 1 Characteristics of patients who received advanced neurointerventional procedures*

\begin{tabular}{|c|c|c|c|}
\hline Characteristics & $\begin{array}{l}\text { No neuro-intervention } \\
(n=185)\end{array}$ & $\begin{array}{l}\text { Neuro-intervention* } \\
(n=22)\end{array}$ & p-value \\
\hline Age (IQR) & $74(62-81)$ & $80(60-85)$ & 0.2 \\
\hline Female & $45 \%$ & $32 \%$ & 0.3 \\
\hline Transferred & $45 \%$ & $64 \%$ & 0.1 \\
\hline Initial NIHSS (IQR) & $7(3-12)$ & $20(10-22)$ & 0.0001 \\
\hline Time (h) to presentation (IQR) & $4(2-6)$ & $3.6(2.5-4.5)$ & 0.2 \\
\hline Proximal occlusion on CTA & $30 \%$ & $86 \%$ & $<0.001$ \\
\hline IV rtPA & $24 \%$ & $32 \%$ & 0.4 \\
\hline Length of stay (days) (IQR) & $5(3-7)$ & $8(7-15)$ & $<0.001$ \\
\hline Outcome: & & & 0.007 \\
\hline Death & $13 \%$ & $27 \%$ & \\
\hline Rehab & $49 \%$ & $64 \%$ & \\
\hline Home & $38 \%$ & $9 \%$ & \\
\hline
\end{tabular}

*Neurointerventional procedures included intra-arterial thrombolysis, intra-arterial mechanical clot retrieval or manipulation, or any neurosurgical procedure. $\mathrm{IQR}$, interquartile range; SD, standard deviation. 
Table 2 Comparing patients with and without proximal cerebral arterial occlusion on CTA

\begin{tabular}{llll}
\hline Characteristics & $\begin{array}{l}\text { No proximal occlusion } \\
(\boldsymbol{n = 1 3 3 )}\end{array}$ & $\begin{array}{l}\text { Proximal occlusion } \\
(\boldsymbol{n}=\mathbf{7 4})\end{array}$ & p-value \\
\hline Age (IQR) & $72(60-80)$ & $76(68-83)$ & 0.04 \\
Female & $46 \%$ & $39 \%$ & 0.4 \\
Transferred & $43 \%$ & $54 \%$ & 0.14 \\
NIHSS (IQR) & $4(2-9)$ & $17(9-21)$ & 0.0001 \\
Time (h) to presentation (IQR) & $4(2.1-6)$ & $3.8(1.8-5.6)$ & 0.3 \\
IV rtPA & $17 \%$ & $38 \%$ & 0.002 \\
Length of stay (days) (IQR) & $4(3-7)$ & $6(4-10)$ & 0.0001 \\
Neuroscience ICU stay & $35 \%$ & $85 \%$ & $<0.0001$ \\
Any neurointervention & $2 \%$ & $26 \%$ & $<0.001$ \\
Neurosurgical intervention & $2 \%$ & $5 \%$ & 0.2 \\
IA thrombolysis & $0 \%$ & $9 \%$ & 0.001 \\
Mechanical IA procedure & $0 \%$ & $19 \%$ & $<0.0001$ \\
Outcome: & $6 \%$ & & $<0.001$ \\
$\quad$ Death & $45 \%$ & $30 \%$ & \\
$\quad$ Rehab & $49 \%$ & $61 \%$ & \\
$\quad$ Home & $9 \%$ & \\
\hline
\end{tabular}

ICU, intensive care unit; IA, intra-arterial; IQR, interquartile range; SD, standard deviation.

independent information even when controlling for NIHSS. In particular, NIHSS is known to be influenced by location because it is so heavily weighted toward language function, with posterior circulation occlusions leading to a lower initial NIHSS but a worse clinical outcome $[28,29]$.

The major limitation of our study design is that it is a single center retrospective cohort. We chose this design for our initial analysis because our center routinely performs CTA on almost all stroke patients, minimizing selection bias. However, patients presenting to an academic center with available tertiary care services may not reflect the full range of ischemic stroke patients that present to community hospitals. More than half of the patients that had proximal occlusions on CTA or received neurointervention were transferred from outside hospitals; this likely reflects a concentrating effect providing a population of more severe strokes than that which might present to any single community hospital. While this enriched our cohort for those that achieved the primary outcome, improving our statistical power, a multicenter study in a larger cohort will be necessary to validate these findings in a more representative population. There may be logistical, financial, and ethical considerations in consenting stroke patients for CTA in other practice settings

Table 3 Predictors of need for any advanced neurointervention using multivariable analysis

\begin{tabular}{lll}
\hline Variable & OR $(\mathbf{9 5} \% \mathbf{C I})$ & p-value \\
\hline NIHSS (per unit increase) & $1.1(1.01-1.2)$ & 0.03 \\
Proximal cerebral artery occlusion & $8.5(2.2-33)$ & 0.002 \\
\hline
\end{tabular}

where it is not routine, but our results appear to provide justification for such a larger, prospective study of the use of CTA to guide transfer decisions.

Another limitation was the exclusion of those who were unable to undergo CTA, most often due to IV contrast allergy and renal insufficiency. While many such patients would also be excluded from interventional neuroradiological procedures, it is possible that some would still have been candidates. Also, there is the possibility that CTA, performed at centers unaccustomed to acquiring it during acute stroke or at off hours, might perform an inadequate study that could delay treatment or transfer decisions, or preclude repetition of the study at the receiving facility.

Finally, the CTA findings were used in clinical decision making, potentially confounding our analysis. This likely overestimates the association of CTA proximal occlusion and neurointervention. Unfortunately, it would likely be unethical to "blind" clinical decision makers to CTA findings. In addition, our primary goal was to aid emergency physicians in predicting clinical options that would ultimately be offered to patients, and in a real world setting such decisions are expected to incorporate all available clinical and radiographic data.

Several factors must be considered prior to incorporating the use of emergency CTA in transfer decisions. AHA guidelines highlight that decision-making regarding IV thrombolytics should not be delayed for vascular imaging such as CTA, and protocols would need to be in place to ensure that treatment decisions for IV rtPA are made prior to initiation of further imaging $[1,22]$. Options can include only performing this test after IV 
Table 4 Test characteristics of proximal cerebral artery occlusion on CTA predicting need for neurointervention

\begin{tabular}{lllll}
\hline & Sensitivity (95\% CI) & Specificity & PPV & NPV \\
\hline Any neuro-intervention* $^{*}$ & $82 \%(59-94 \%)$ & $71 \%(64-77 \%)$ & $25 \%(16-37 \%)$ & $97 \%(92-99 \%)$ \\
\hline IA thrombolysis & $86 \%(49-97 \%)$ & $67 \%(66-67 \%)$ & $8 \%(5-9 \%)$ & $99 \%(97-99 \%)$ \\
\hline Mechanical IA procedure & $100 \%(79-100 \%)$ & $70 \%(69-70 \%)$ & $19 \%(15-19 \%)$ & $100 \%(98-100 \%)$ \\
\hline
\end{tabular}

IA, intra-arterial; PPV, positive predictive value; NPV, negative predictive value.

${ }^{*}$ Any neurointervention includes IA thrombolysis, IA mechanical clot retrieval or manipulation, or any neurosurgical procedure.

thrombolysis in eligible patients, or only for those in whom decision-making would be changed based on the results. A rapid CTA can take less than $10 \mathrm{~min}$ to acquire, and the source images are available immediately on the CT scanner workstation. These images can then be rapidly processed and examined to detect proximal artery occlusion, and further studies should validate the ability of plain radiography technicians to generate the images and general radiologists or emergency physicians to reliably diagnose these occlusions. Another concern is the use of IV contrast, which can carry the risk of allergic reaction or contrast-induced nephropathy (CIN). Although traditionally thought to occur in $2-3 \%$ of cases, the risk of nephropathy after stroke or hospitalization is similar even without contrast, and many cases of CIN may simply be due to the nephropathy associated with hospitalization [30-36]. Finally, protocols should be in place to ensure that the study would not need to be repeated upon arrival to a tertiary care center, either due to an inadequate initial study or problems with image transfer between facilities. Prearranged transfer agreements, or even remote consultation via telephone or telemedicine [37], can ensure appropriate usage and communication.

\section{Conclusions}

In summary, the finding of a large proximal cerebral arterial occlusion on CTA predicts the use of neurointerventional services in patients with acute ischemic stroke. Thus, our results provide justification for conducting future prospective studies on using CTA as a rapid decision-making tool to select patients who may be candidates for endovascular therapies at CSCs.

\footnotetext{
Abbreviations

AHA: American Heart Association; CIN: contrast induced nephropathy; CSC: comprehensive stroke center; CTA: computed tomography angiography; ED: emergency department; IA: intra-arterial; ICU: intensive care unit; IV: intravenous; MRA: magnetic resonance angiography; MRI: magnetic resonance imaging; NIHSS: NIH stroke scale; PSC: primary stroke center; rtPA: recombinant tissue plasminogen activator
}

\section{Acknowledgements}

This work was supported by the Harvard Affiliated Emergency Medicine Residency Richard Wuerz Scholarship for Emergency Medicine Research and Public Health Service Award K23NS059774.

Patient consent

Patient consent was waived by the IRB since this was a retrospective review.

\section{Author details}

'Department of Emergency Medicine, Massachusetts General Hospital, Boston, MA, USA ²Department of Radiology, Massachusetts General Hospital, Boston, MA, USA ${ }^{3}$ Department of Medicine, Massachusetts General Hospital, Boston, MA, USA ${ }^{4}$ Department of Neurology, Massachusetts General Hospital, Boston, MA, USA

\section{Authors' contributions}

LET gathered data, performed analyses, and drafted the manuscript. JNG performed statistical analyses, developed study design, and critically revised the manuscript for important intellectual content. RH gathered data and reviewed all imaging. AJY provided critical revision of the manuscript and figures for important intellectual content. LHS provided advice on analysis and critical revision of the manuscript for important intellectual content. RGG conceived the study, supervised data collection, and imaging analyses, and critically revised the manuscript for important intellectual content. All authors read and approved the manuscript.

\section{Competing interests}

The authors declare that they have no competing interests.

Received: 12 March 2011 Accepted: 3 October 2011

Published: 3 October 2011

\section{References}

1. Adams HP Jr, del Zoppo G, Alberts MJ, Bhatt DL, Brass L, Furlan A, Grubb RL, Higashida RT, Jauch EC, Kidwell C, Lyden PD, Morgenstern LB, Qureshi Al, Rosenwasser RH, Scott PA, Wijdicks EF, American Heart Association, American Stroke Association Stroke Council, Clinical Cardiology Council, Cardiovascular Radiology and Intervention Council, Atherosclerotic Peripheral Vascular Disease and Quality of Care Outcomes in Research Interdisciplinary Working Groups: Guidelines for the early management of adults with ischemic stroke: a guideline from the American Heart Association/American Stroke Association Stroke Council, Clinical Cardiology Council, Cardiovascular Radiology and Intervention Council, and the Atherosclerotic Peripheral Vascular Disease and Quality of Care Outcomes in Research Interdisciplinary Working Groups: the American Academy of Neurology affirms the value of this guideline as an educational tool for neurologists. Stroke 2007, 38:1655-1711.

2. Chenkin J, Gladstone DJ, Verbeek PR, Lindsay P, Fang J, Black SE, Morrison L: Predictive value of the Ontario prehospital stroke screening tool for the identification of patients with acute stroke. Prehosp Emerg Care 2009, 13:153-159.

3. Alberts MJ, Hademenos G, Latchaw RE, Jagoda A, Marler JR, Mayberg MR, Starke RD, Todd HW, Viste KM, Girgus M, Shephard T, Emr M, Shwayder P, Walker MD: Recommendations for the establishment of primary stroke centers. Brain Attack Coalition. JAMA 2000, 283:3102-3109.

4. Alberts MJ, Latchaw RE, Selman WR, Shephard T, Hadley MN, Brass LM, Koroshetz W, Marler JR, Booss J, Zorowitz RD, Croft JB, Magnis E, Mulligan D, Jagoda A, O'Connor R, Cawley CM, Connors JJ, RoseDeRenzy JA, Emr M, Warren M, Walker MD, Brain Attack Coalition: Recommendations for comprehensive stroke centers: a consensus statement from the Brain Attack Coalition. Stroke 2005, 36:1597-1616.

5. Lev MH, Farkas J, Rodriguez VR, Schwamm LH, Hunter GJ, Putman CM, Rordorf GA, Buonanno FS, Budzik R, Koroshetz WJ, Gonzalez RG: CT angiography in the rapid triage of patients with hyperacute stroke to intraarterial thrombolysis: accuracy in the detection of large vessel thrombus. J Comput Assist Tomogr 2001, 25:520-528.

6. Torres-Mozqueda F, He J, Yeh IB, Schwamm LH, Lev MH, Schaefer PW, Gonzalez RG: An acute ischemic stroke classification instrument that 
includes CT or MR angiography: the Boston Acute Stroke Imaging Scale. AJNR Am J Neuroradiol 2008, 29:1111-1117.

7. Cipriano LE, Steinberg ML, Gazelle GS, Gonzalez RG: Comparing and predicting the costs and outcomes of patients with major and minor stroke using the Boston Acute Stroke Imaging Scale neuroimaging classification system. AJNR Am J Neuroradiol 2009, 30:703-709.

8. Sims JR, Rordorf G, Smith EE, Koroshetz WJ, Lev MH, Buonanno F, Schwamm LH: Arterial occlusion revealed by CT angiography predicts $\mathrm{NIH}$ stroke score and acute outcomes after IV tPA treatment. AJNR Am J Neuroradiol 2005, 26:246-251.

9. Furlan A, Higashida R, Wechsler L, Gent M, Rowley H, Kase C, Pessin M, Ahuja A, Callahan F, Clark WM, Silver F, Rivera F: Intra-arterial prourokinase for acute ischemic stroke. The PROACT II study: a randomized controlled trial. Prolyse in Acute Cerebral Thromboembolism. JAMA 1999, 282:2003-2011.

10. Lisboa RC, Jovanovic BD, Alberts MJ: Analysis of the safety and efficacy of intra-arterial thrombolytic therapy in ischemic stroke. Stroke 2002, 33:2866-2871.

11. Noser EA, Shaltoni HM, Hall CE, Alexandrov AV, Garami Z, Cacayorin ED, Song JK, Grotta JC, Campbell MS: Aggressive mechanical clot disruption: a safe adjunct to thrombolytic therapy in acute stroke? Stroke 2005, 36:292-296.

12. Brekenfeld C, Remonda L, Nedeltchev K, v Bredow F, Ozdoba C, Wiest R, Arnold M, Mattle HP, Schroth G: Endovascular neuroradiological treatment of acute ischemic stroke: techniques and results in 350 patients. Neurol Res 2005, 27(Suppl 1):S29-35.

13. Smith WS, Sung G, Starkman S, Saver JL, Kidwell CS, Gobin YP, Lutsep HL, Nesbit GM, Grobelny T, Rymer MM, Silverman IE, Higashida RT, Budzik RF, Marks MP, MERCI Trial Investigators: Safety and efficacy of mechanical embolectomy in acute ischemic stroke: results of the MERCI trial. Stroke 2005, 36:1432-1438.

14. Smith WS, Sung G, Saver J, Budzik R, Duckwiler G, Liebeskind DS, Lutsep HL, Rymer MM, Higashida RT, Starkman S, Gobin YP, Multi MERCI Investigators, Frei D, Grobelny T, Hellinger F, Huddle D, Kidwell C, Koroshetz W, Marks M, Nesbit G, Silverman IE: Mechanical thrombectomy for acute ischemic stroke: final results of the Multi MERCI trial. Stroke 2008, 39:1205-1212.

15. Penumbra Pivotal Stroke Trial Investigators: The penumbra pivotal stroke trial: safety and effectiveness of a new generation of mechanical devices for clot removal in intracranial large vessel occlusive disease. Stroke 2009, 40:2761-2768.

16. Rha JH, Saver JL: The impact of recanalization on ischemic stroke outcome: a meta-analysis. Stroke 2007, 38:967-973.

17. Ginde AA, Foianini A, Renner DM, Valley M, Camargo CA Jr: Availability and quality of computed tomography and magnetic resonance imaging equipment in US emergency departments. Acad Emerg Med 2008, 15:780-783.

18. Smith WS, Tsao JW, Billings ME, Johnston SC, Hemphill JC, Bonovich DC, Dillon WP: Prognostic significance of angiographically confirmed large vessel intracranial occlusion in patients presenting with acute brain ischemia. Neurocrit Care 2006, 4:14-17.

19. Hacke W, Furlan AJ, Al-Rawi Y, Davalos A, Fiebach JB, Gruber F, Kaste M, Lipka L, Pedraza S, Ringleb PA, Rowley HA, Schneider D, Schwamm LH, Leal JS, Sohngen M, Teal PA, Wilhelm-Ogunbiyi K, Wintermark M, Warach S: Intravenous desmoteplase in patients with acute ischaemic stroke selected by MRI perfusion-diffusion weighted imaging or perfusion CT (DIAS-2): a prospective, randomised, double-blind, placebo-controlled study. Lancet Neurol 2009, 8:141-150.

20. Mattle HP, Arnold M, Georgiadis D, Baumann C, Nedeltchev K, Benninger D, Remonda L, von Budingen C, Diana A, Pangalu A, Schroth G,

Baumgartner RW: Comparison of intraarterial and intravenous thrombolysis for ischemic stroke with hyperdense middle cerebral artery sign. Stroke 2008, 39:379-383.

21. Sen S, Huang DY, Akhavan O, Wilson S, Verro P, Solander S: IV vs. IA TPA in acute ischemic stroke with $C T$ angiographic evidence of major vessel occlusion: a feasibility study. Neurocrit Care 2009, 11:76-81.

22. Latchaw RE, Alberts MJ, Lev MH, Connors JJ, Harbaugh RE, Higashida RT, Hobson R, Kidwell CS, Koroshetz WJ, Mathews V, Villablanca P, Warach S, Walters B, The American Heart Association Council on Cardiovascular Radiology and Intervention, Stroke Council, The Interdisciplinary Council on Peripheral Vascular Disease: Recommendations for Imaging of Acute
Ischemic Stroke. A Scientific Statement From the American Heart Association. Stroke 2009, 40:3646-3678.

23. Derex L, Nighoghossian N, Hermier M, Adeleine P, Froment JC, Trouillas P: Early detection of cerebral arterial occlusion on magnetic resonance angiography: predictive value of the baseline NIHSS score and impact on neurological outcome. Cerebrovasc Dis 2002, 13:225-229.

24. Lewandowski CA, Frankel M, Tomsick TA, Broderick J, Frey J, Clark W. Starkman S, Grotta J, Spilker J, Khoury J, Brott T: Combined intravenous and intra-arterial r-TPA versus intra-arterial therapy of acute ischemic stroke: Emergency Management of Stroke (EMS) Bridging Trial. Stroke 1999, 30:2598-2605.

25. Nakajima M, Kimura K, Ogata T, Takada T, Uchino M, Minematsu K: Relationships between angiographic findings and National Institutes of Health stroke scale score in cases of hyperacute carotid ischemic stroke. AJNR Am J Neuroradiol 2004, 25:238-241.

26. Fischer U, Arnold M, Nedeltchev K, Brekenfeld C, Ballinari P, Remonda L Schroth G, Mattle HP: NIHSS score and arteriographic findings in acute ischemic stroke. Stroke 2005, 36:2121-2125.

27. Maas MB, Furie KL, Lev MH, Ay H, Singhal AB, Greer DM, Harris GJ, Halpern E, Koroshetz WJ, Smith WS: National Institutes of Health Stroke Scale Score Is Poorly Predictive of Proximal Occlusion in Acute Cerebral Ischemia. Stroke 2009, 40:2988-2993.

28. Sato S, Toyoda K, Uehara T, Toratani N, Yokota C, Moriwaki H, Naritomi H, Minematsu K: Baseline NIH Stroke Scale Score predicting outcome in anterior and posterior circulation strokes. Neurology 2008, 70:2371-2377.

29. Linfante I, Llinas RH, Schlaug G, Chaves C, Warach S, Caplan LR: Diffusionweighted imaging and National Institutes of Health Stroke Scale in the acute phase of posterior-circulation stroke. Arch Neurol 2001, 58:621-628.

30. Gleeson TG, Bulugahapitiya S: Contrast-induced nephropathy. AJR Am J Roentgenol 2004, 183:1673-1689.

31. Dittrich R, Akdeniz S, Kloska SP, Fischer T, Ritter MA, Seidensticker P, Heindel W, Ringelstein EB, Nabavi DG: Low rate of contrast-induced Nephropathy after CT perfusion and CT angiography in acute stroke patients. J Neurol 2007, 254:1491-1497.

32. Hopyan JJ, Gladstone DJ, Mallia G, Schiff J, Fox AJ, Symons SP, Buck BH, Black SE, Aviv Rl: Renal safety of $\mathrm{CT}$ angiography and perfusion imaging in the emergency evaluation of acute stroke. AJNR Am J Neuroradiol 2008, 29:1826-1830.

33. Krol AL, Dzialowski I, Roy J, Puetz V, Subramaniam S, Coutts SB, Demchuk AM: Incidence of radiocontrast nephropathy in patients undergoing acute stroke computed tomography angiography. Stroke 2007, 38:2364-2366.

34. Oleinik A, Romero JM, Schwab K, Lev MH, Jhawar N, Delgado Almandoz JE, Smith EE, Greenberg SM, Rosand J, Goldstein JN: CT angiography for intracerebral hemorrhage does not increase risk of acute nephropathy. Stroke 2009, 40:2393-2397.

35. Baumgarten DA, Ellis JH: Contrast-induced nephropathy: contrast material not required? AJR Am J Roentgenol 2008, 191:383-386.

36. Lima FO, Lev MH, Levy RA, Silva GS, Ebril M, de Camargo EC, Pomerantz S, Singhal AB, Greer DM, Ay H, Gonzalez RG, Koroshetz WJ, Smith WS, Furie KL: Functional Contrast-Enhanced CT For Evaluation of Acute Ischemic Stroke Does Not Increase the Risk of Contrast-Induced Nephropathy. AJNR Am J Neuroradiol 2010, 31:817-821.

37. Meyer BC, Raman R, Hemmen T, Obler R, Zivin JA, Rao R, Thomas RG, Lyden PD: Efficacy of site-independent telemedicine in the STRokE DOC trial: a randomised, blinded, prospective study. Lancet Neurol 2008, 7:787-795

doi:10.1186/1865-1380-4-62

Cite this article as: Thomas et al.: CT angiography predicts use of tertiary interventional services in acute ischemic stroke patients. International Journal of Emergency Medicine 2011 4:62. 